\title{
Avaliação de desempenho das concentrações capilares de zinco como método diagnóstico da deficiência de zinco: um estudo comparativo com as concentrações séricas de zinco
}

\author{
Performance evaluation of hair zinc levels as a \\ diagnostic method of zinc deficiency: A \\ comparative study with serum zinc
}

Dixis FIGUEROA PEDRAZA'

Márcia Cristina SALES'

RE S U M O

\section{Objetivo}

Examinar o poder diagnóstico de deficiência de zinco das concentrações capilares desse mineral por meio da comparação com as concentrações séricas.

\section{Métodos}

Estudo transversal desenvolvido com 170 crianças na faixa etária dos 12 aos 72 meses. A análise da Curva Característica de Operação do Receptor foi utilizada para identificar a sensibilidade e a especificidade do melhor ponto de corte para o diagnóstico da deficiência de zinco no cabelo. Verificou-se ainda a significância estatística da área sob a curva.

\section{Resultados}

O ponto de corte apontado como ótimo para o zinco no cabelo foi de 292,52ppm (sensibilidade de 55,6\% e especificidade de 60,8\%), com uma área sob a curva de 0,549, sem significância estatística.

\section{Conclusão}

O diagnóstico da deficiência de zinco pelas concentrações capilares desse elemento, em comparação às concentrações séricas de zinco, mostra baixa sensibilidade e ponto de corte ideal superior ao sugerido. Permanece, ainda, a necessidade de novos estudos que possibilitem a obtenção de indicadores bioquímicos mais sensíveis

${ }^{1}$ Universidade Estadual da Paraíba, Departamento de Enfermagem, Programa de Pós-Graduação em Saúde Pública. Av. das Baraúnas, 351, Bodocongó, 58429-500, Campina Grande, PB, Brasil. Correspondência para/Correspondence to: D FIGUEROA PEDRAZA. E-mail: <dixisfigueroa@gmail.com>.

Apoio: Projeto de Pesquisa financiado pela Universidade Estadual da Paraíba (Processo no 056/2008). 
618 D FIGUEROA PEDRAZA \& MC SALES

e específicos para o diagnóstico da deficiência de zinco na população, sob tudo sem importantes limitações técnicas.

Termos de indexação: Criança. Diagnóstico. Estado nutricional. Marcadores biológicos. Sensibilidade e especificidade. Zinco.

\section{A B S T R A C T}

\section{Objective}

This study examined the power of hair zinc concentration to diagnose zinc deficiency by comparing hair zinc concentration with serum zinc level.

\section{Methods}

This cross-sectional study included 170 children aged 12 to 72 months. The receiver operating characteristic curve was used for determining the sensitivity and specificity of the best cutoff point for diagnosing zinc deficiency in hair. The statistical significance of the area under the curve was also verified.

\section{Results}

The best cutoff for zinc concentration in hair was 292.52ppm (sensitivity of 55.6\%, a specificity of 60.8\%), with an area under the curve of 0.549 , without statistical significance.

\section{Conclusion}

Diagnosis of zinc deficiency based on hair zinc concentration compared with serum zinc level has low sensitivity and its ideal cutoff is higher than the suggested cutoff. New studies are needed to research more sensitive and specific biochemical indicators of zinc deficiency, especially indicators without important technical limitations.

Indexing terms: Child. Diagnosis. Nutritional status. Biological markers. Sensitivity and specificity. Zinc.

\section{N T R O D U Ç Ã O}

O zinco é um elemento-traço de ampla distribuição no corpo humano, sendo necessário para a atividade de mais de 200 enzimas envolvidas na manutenção de importantes vias metabólicas do organismo ${ }^{1}$. A deficiência de zinco está associada à maior ocorrência de disfunções bioquímicas, imunológicas e clínicas, tais como acrodermatite enteropática, anorexia, hipogonadismo, intolerância à glicose, fragilidade osmótica dos eritrócitos, restrição da utilização de vitamina A e desordens de comportamento, aprendizado e memória². Na infância, a carência desse mineral pode ainda ocasionar deficit de crescimento e aumento da mortalidade infantil por doenças respiratórias e diarreia ${ }^{2-4}$.

Estima-se que a deficiência de zinco acometa cerca de um terço da população mundial ${ }^{5}$, podendo ser considerada potencialmente um problema de saúde pública em diversos países em desenvolvimento ${ }^{6}$. As crianças apresentam-se co- mo um dos grupos populacionais mais vulneráveis à ocorrência dessa carência nutricional ${ }^{7}$. No Brasil, estudos realizados a partir de diferentes indicadores apontam baixos níveis de zinco na população infantil|6,8-10.

O melhor indicador do risco de deficiência de zinco nas populações é a concentração de zinco no soro ou plasma ${ }^{11}$, recomendado pela World Health Organization (WHO), International Atomic Energy Agency (IAEA) e International Zinc Nutrition Consultative Group (IZiNCG) ${ }^{12}$, pois reflete o consumo dietético de zinco, responde consistentemente à suplementação com zinco, e estão disponíveis os dados de referência apropriados para idade, sexo, hora do dia e tempo decorrido desde a última refeição ${ }^{11}$. Contudo, os dados de prevalência de deficiência desse elemento, no Brasil e no mundo, ainda são escassos. Este fato está relacionado aos elevados custos das análises laboratoriais e suas dificuldades técnicas condicionadas à obtenção da amostra, análises de laboratório e interpretação dos resultados ${ }^{11,13,14}$. 
Desse modo, o IZiNCG recomenda, alternativamente, o uso das concentrações de zinco capilar para caracterizar o estado nutricional desse elemento, cuja determinação no cabelo apresenta vantagens em relação às concentrações séricas por ser um procedimento menos invasivo, de mais fácil obtenção e estabilidade durante o transporte e armazenagem ${ }^{15}$.

Neste contexto, o presente trabalho objetiva examinar o poder diagnóstico de deficiência de zinco das concentrações capilares desse elemento por meio da comparação com as concentrações séricas de zinco.

\section{MÉTODOS}

As crianças que fazem parte deste estudo estão na faixa etária dos 12 aos 72 meses e foram selecionadas nas creches da Secretaria de Estado do Desenvolvimento Humano do Governo da Paraíba. Funcionavam, na época do estudo, 45 creches em bairros distintos das cidades beneficiadas, situadas, geralmente, em áreas carentes que abrigam crianças de famílias de baixa renda (percebem uma renda familiar entre um e dois salários-mínimos). O benefício está presente em oito municípios paraibanos: João Pessoa (30 creches), Campina Grande (9 creches), além das cidades de Areia, Bayeux, Mamanguape, Itaporanga, Soledade e Umbuzeiro (cada uma delas com uma creche). Ao todo, 3310 crianças são beneficiadas, sendo, aproximadamente, 2317 do município de João Pessoa, 621 do município de Campina Grande e 372 dos outros municípios.

Foi selecionada uma amostra probabilística de creches da Secretaria de Estado do Desenvolvimento Humano do Governo da Paraíba, por meio de um procedimento de amostragem em duas etapas. Para garantir a representatividade dos municípios, o sistema de referência para a primeira etapa de amostragem foi ordenado segundo estratos (João Pessoa, Campina Grande, outros municípios), possibilitando a obtenção de um tamanho amostral apropriado para cada estrato. Considerou-se também o porte da creche (número de crianças por creche). Na segunda etapa de amostragem, foram sorteadas, nas 14 creches selecionadas de forma aleatória na primeira etapa, as crianças a serem avaliadas. A opção para determinar o tamanho da amostra do estudo foi o procedimento de amostragem para proporções:

$$
\mathrm{n}=\frac{\mathrm{N}^{*} \mathrm{Z}_{\alpha}{ }^{2 *} p^{*} \mathrm{q}}{\mathrm{d}^{2 *}(\mathrm{~N}-1)+\mathrm{Z}_{\alpha}^{2 *} p}
$$

onde N é o total da população, $Z \alpha^{2}=1962$ (se a confiança é de $95 \%$ ), $p$ é a proporção esperada, $q=1-p, d$ é a precisão arbitrária (erro de estimação). Considerou-se $p=7,0 \%$ (média do deficit de estatura no Brasil segundo dados da Pesquisa Nacional de Demografia e Saúde da Mulher e da Criança $^{16}$ ) e $d=3 \%$, totalizando 256 crianças. Esse valor foi corrigido em 10\% devido à possibilidade de poder compensar eventuais perdas, ficando estabelecida a amostra de 282 crianças que foram escolhidas de forma aleatória no momento do trabalho de campo.

\section{Coleta de dados e classificação do estado nutricional}

A coleta de dados foi realizada nas creches, de forma transversal, em 2009. Os dados relativos ao sexo e à idade das crianças foram obtidos a partir de questionário específico.

A coleta de sangue foi realizada por técnico de laboratório com experiência em crianças. Realizou-se a coleta sanguínea de uma veia do antebraço da criança. Foram utilizados tubos a vácuo próprios para análise de elementos traço (Vacutainer ${ }^{\circledR}$, tubos a vácuo transparentes "trace free", Beckton Dickinson Inc, Lakes NJ, EUA). As coletas de sangue sempre aconteceram antes de o almoço ser oferecido às crianças, objetivando padronizar o período do dia bem como o tempo médio de jejum de cada indivíduo, controlando, portanto, estes fatores. Os procedimentos para a 
coleta e o processamento das amostras para determinação das concentrações de zinco no soro obedeceram às recomendações do IZiNCG ${ }^{15}$.

Para a obtenção das amostras de cabelo, os entrevistadores participaram de treinamento realizado por pesquisadores com experiência previa do Centro de Investigação em Micronutrientes da Universidade Federal da Paraíba. Os procedimentos para coleta e processamento das amostras para determinação das concentrações de zinco capilar obedeceram às recomendações feitas por Harrison et al. ${ }^{17}$.

Os níveis de zinco no soro e no cabelo foram determinados mediante Espectrofotometria de Absorção Atômica de Chama, empregando Espectrofotômetro Analyst 300 (PerkinElmer Norwalk, Ct, EUA), modelo 3100 a uma longitude de onda de $213 \mathrm{~nm}$ e com ar-acetileno ${ }^{18}$. Concentrações de zinco sérico $<65 \mu \mathrm{g} / \mathrm{dL}$ foram considerados para indicar deficiência de zinco no soro ${ }^{11}$. Concentrações de zinco no cabelo $<70 p p m$ foram consideradas indicativas de deficiência de zinco capilar ${ }^{19}$.

Dado que as infecções podem diminuir as concentrações de zinco no soro ${ }^{14}$, a presença de infecção subclínica foi controlada através da determinação da Proteína C-Reativa (PCR), por técnica imunoturbidimétrica (Cobas Fara Analyzer, Roche Products, Welwyn, UK), segundo orientações do fabricante. Valores de PCR $\geq 6,0 \mathrm{mg} / \mathrm{L}$ foram utilizados para a identificação de infecção subclínica ${ }^{20}$.

As determinações de zinco no soro foram realizadas no Instituto Hermes Pardini, as de zinco no cabelo, no Laboratório de Análises Minerais, Solos e Água do Departamento de Engenharia Química da Universidade Federal de Pernambuco, e as de PCR, no Laboratório de Análises Clínicas da Universidade Estadual da Paraíba.

\section{Análises estatísticas}

Os pontos de corte para deficiência de zinco no cabelo foram determinados por meio da curva Receinver Operating Characteristic (ROC,
Característica de Operação do Receptor). As curvas ROC constituem uma representação gráfica da sensibilidade (eixo vertical) e o complementar da especificidade (eixo horizontal) para diversos pontos de corte, que permitem identificar o melhor deles. Foi determinada a área sob a curva ROC e os Intervalos de Confiança (IC95\%). Na interpretação dos resultados, considera-se que quanto maior a área sob a curva ROC, maior o poder de discriminação do indicador para o diagnóstico da deficiência de zinco, não devendo o limite inferior do intervalo de confiança atingir 0,5021. Para delimitar desempenho satisfatório do teste diagnóstico, considerou-se área sob a curva ROC acima de 0,7022.

As análises de significância estatística foram realizadas por meio dos softwares Excel 2000 e R v2.10.0, sendo todas as conclusões tomadas ao nível de significância de 5\%.

A digitação dos dados foi realizada com dupla entrada, imediatamente após a coleta da informação, em planilhas do programa Excel (Microsoft Inc., Estados Unidos), de maneira tal que possibilitou a unificação entre eles através de uma única variável identificadora da criança. Após o término da digitação, os dois bancos de dados foram cruzados com a utilização do aplicativo Validate do programa Epi Info versão 6.04b, possibilitando, assim, verificar a consistência dos dados e gerar o banco final, que foi usado para análise estatística. Todas as informações contidas nas fichas foram revisadas e debatidas antes da digitação.

\section{Aspectos éticos}

O projeto foi apreciado e aprovado pelo Comitê de Ética em Pesquisa da Universidade Estadual da Paraíba, protocolado sob o número 0021.0.133.000-09. As coletas de dados das crianças e das mães foram realizadas após consentimento informado das mães ou responsáveis. Uma vez com os resultados, os pais foram conta- 
tados para esclarecimentos acerca do estado de saúde das crianças e correspondentes orientações nutricionais.

\section{RES U LTA D OS}

Do total de 282 crianças, registraram-se seis recusas e 12 perdas (problemas relacionados à coleta de sangue: sangue insuficiente ou hemólise das amostras). Foram excluídas das análises as crianças com marcador de processos infecciosos subclínicos $(n=24)$ e as crianças cujos parâmetros bioquímicos apresentaram valores considerados extremos (outliers) na distribuição de dados $(n=4)$. Constituíram a amostra deste estudo as crianças que tiveram tanto as concentrações de zinco sérico como as de zinco no cabelo avaliadas $(n=170)$.

A Tabela 1 apresenta os valores de sensibilidade, especificidade e a área sob a curva ROC do estado nutricional, relativo ao zinco capilar. Tomando-se como padrão os valores diagnósticos da deficiência de zinco no soro ( $<65 \mu \mathrm{g} / \mathrm{dL})$, o ponto de corte apontado como ótimo para o zinco capilar foi de 292,52ppm. Este ponto corresponde a uma sensibilidade de 55,6\%, IC $95 \%$ (35,3\% - 74,5\%) e uma especificidade de 60,8\%, IC95\% (52,3\% - 68,9\%), com uma área sob a curva ROC de 0,549.

\section{I S C U S S Ã O}

A análise da sensibilidade e especificidade de exames diagnósticos por meio da construção de curvas ROC tem sido recomendada em estudos epidemiológicos para a determinação de pontos de corte. Esse tipo de análise fornece também a área sob a curva, a qual traduz o poder de discriminação de um indicador para um determinado desfecho ${ }^{21}$.

Os dados desta pesquisa mostram a concentração de zinco capilar como um teste de menor sensibilidade $(55,6 \%)$ e maior especificidade $(60,8 \%)$, o que gera uma menor quantidade de diagnósticos classificados como falso-positivo, diferentemente dos falso-negativos ${ }^{23}$. Implicações práticas advêm como consequência dessa constatação, pois o uso de indicadores de baixa sensibilidade pode acarretar uma subestimação do número de casos da doença, o que implica a não recomendação de testes de baixa sensibilidade. O fato poderia comprometer o êxito de programas de intervenção, haja vista que indivíduos com carência nutricional deixariam de receber o tratamento adequado. Em contrapartida, a inclusão de muitos falso-positivos, derivados de um teste de baixa especificidade, poderia levar à inclusão de indivíduos sadios em programas de intervenção, dilapidando recursos que poderiam ser aproveitados em outras tarefas, além de submeter indivíduos a efeitos colaterais indesejáveis (neste caso, relacionados ao excesso de zinco no organismo) ${ }^{24}$.

Neste estudo, o ponto da curva ROC que conferiu o maior valor de sensibilidade e especificidade para o diagnóstico da deficiência de zinco capilar foi de 292,52ppm, valor acima daquele proposto no estudo de Buzina e colaboradores $(70 \mathrm{ppm})^{19}$. A adoção desses pontos de corte implicaria uma maior quantidade de crianças

Tabela 1. Sensibilidade, especificidade e área sob a curva ROC estimadas para as concentrações capilares de zinco por meio da comparação com as concentrações séricas desse mineral. Paraíba, 2009.

\begin{tabular}{|c|c|c|c|c|c|c|c|c|c|c|}
\hline Zinco no cabelo & Sensibilidade & IC95\% & Especificidade & IC95\% & LR+ & LR- & $\mathrm{VP}+$ & VP- & AUC & $p$-valor \\
\hline$<11,31 \mathrm{ppm}$ & 96,3 & $81,0-99,4$ & 0,7 & $0,1-3,8$ & 1,0 & 5,3 & 15,5 & 50,0 & & \\
\hline$<292,52 \mathrm{ppm}$ & 55,6 & $35,3-74,5$ & 60,8 & $52,3-68,9$ & 1,4 & 0,7 & 21,1 & 87,9 & 0,549 & 0,424 \\
\hline$<714,17 \mathrm{ppm}$ & 7,4 & $1,1-24,3$ & 95,1 & $90,2-98,0$ & 1,5 & 1,0 & 22,2 & 84,5 & & \\
\hline
\end{tabular}

Nota: IC: Intervalo de Confiança; LR+: Likelihood Ratio positive (Razão de verossimilhança positiva); LR-: Likelihood Ratio negative (Razão de verossimilhança negativa); VP+: Valor Preditivo positivo; VP-: Valor Preditivo negativo; AUC: Area Under Curve (Área sob a Curva); ppm: partes por milhão. 
diagnosticadas como deficientes, o que proporcionaria um aumento da prevalência de deficit nutricional. Isso decorre do fato de que alguns indivíduos cujas concentrações de zinco encontravam-se dentro da faixa de normalidade, segundo os critérios adotados, seriam agora incluídos como deficientes. A essencialidade desse resultado decorre da importância que tem a definição de pontos de corte de normalidade no estabelecimento de diagnósticos e medidas de intervenção apropriadas em relação ao estado nutricional ${ }^{25}$.

Os dados desta pesquisa mostram ainda que a área sob a curva ROC para o teste diagnóstico da deficiência de zinco capilar foi de 0,549, o que sugere uma capacidade de diagnóstico correto de pelo menos $55 \%$ dos sujeitos. Considerando que um teste diagnóstico tem desempenho satisfatório quando apresenta uma área sob a curva ROC acima de $0,70^{22}$, reporta-se a baixa capacidade de discriminar indivíduos com deficiência de zinco e indivíduos sem essa deficiência. Sabe-se que alguns fatores podem interferir no metabolismo do zinco, reduzindo o poder de discriminação diagnóstica de indicadores do estado nutricional desse mineral. Vários fatores fisiológicos, como a baixa albumina sérica, contagens elevadas de células brancas no sangue, hemólise, presença de processos inflamatórios e estresse, podem afetar os níveis séricos de zinCO ${ }^{15,26}$. Por sua vez, os níveis de zinco no cabelo podem variar de acordo com o estado de desnutrição, características do cabelo (cor, tamanho, contaminação externa por ar, água, suor, xampus, sabonetes, tratamento capilar etc.) e pela distância do couro cabeludo ao local do corte do cabelo $^{1,15}$. Nesse sentido, ressalta-se a possível influência desses fatores na área sob a curva ROC obtida, sendo considerada uma limitação desta pesquisa a ausência de controle para determinados fatores importantes na interpretação dos resultados, tais como as características do cabelo.

Por fim, os achados desta pesquisa reforçam a importância de estudos de acurácia de testes diagnósticos. O zinco não é certamente o único mineral que apresenta escassez de biomarcadores adequados ${ }^{27}$. Indicadores comumentemente usados no diagnóstico das deficiências de ferro e de vitamina A, tais com o retinol sérico, a hemoglobina e a ferritina, também sofrem a influência de fatores que interferem no seu poder diagnóstico ${ }^{28-30}$. Porém, no caso do zinco, esse fato tem sido especialmente preocupante em virtude das dificuldades que isso traz na realização de estudos epidemiológicos, acarretando problemas na obtenção de dados sobre a prevalência de deficiência de zinco no Brasil e no mundo ${ }^{27}$. Ressalta-se, assim, a importância da validação de pontos de corte para os valores de zinco no cabelo devido à carência de dados que expressem as diferenças por sexo, idade e sazonalidade, bem como às incertezas na interpretação de resultados entre as crianças desnutridas ${ }^{15}$.

A deficiência de zinco tem sido relatada em vários países; porém, sua cartografia ainda não está devidamente caracterizada em termos de magnitude e distribuição espacial. Estima-se que essa carência nutricional possa constituir um potencial problema de saúde pública em diversos países em desenvolvimento ${ }^{6}$, sendo as crianças um dos grupos populacionais mais vulneráveis ${ }^{7}$. Um levantamento nacional realizado no México revelou que $25,3 \%$ das crianças mexicanas com menos de 12 anos apresentavam baixos níveis séricos de zinco ${ }^{31}$. No Brasil, em uma pesquisa realizada com crianças na faixa etária de 1 a 5 anos, verificou-se baixas concentrações de zinco no soro em todas as crianças em estudo ${ }^{10}$. Estes achados alertam a comunidade científica para necessidade de uma melhor compreensão do cenário epidemiológico da deficiência de zinco no Brasil e no mundo. Nesse contexto, a utilização de indicadores que reflitam a realidade sobre o estado nutricional de zinco é essencial.

Dada as dificuldades relatadas, o uso combinado de diferentes indicadores poderia ser uma alternativa. Nesse contexto, se a concentração de zinco no soro representa, como dito, o indicador bioquímico mais fiável ${ }^{11}$, o zinco no cabelo e a fosfatase alcalina, por exemplo, são importantes 
por refletirem deficiências marginais de zinco em diferentes momentos biológicos. A medida da concentração de zinco no cabelo é um parâmetro adequado para avaliar a deficiência crônica, uma vez que esse indicador reflete, principalmente, mudanças de ingestão dietética sucedidas por longos períodos. Entretanto, a medida da atividade da fosfatase alcalina revela o real estado de deficiência, refletindo um consumo insuficiente desse micronutriente no momento presente ${ }^{6}$. Dessa forma, o uso combinado dos indicadores possibilita uma análise dos diferentes estágios de deficiência e contribui para uma maior precisão no diagnóstico da carência nutricional.

\section{O N CLUS Ã O}

O diagnóstico da deficiência de zinco pelas concentrações capilares de zinco, em comparação às concentrações séricas desse mineral, mostra baixa sensibilidade e ponto de corte ideal superior ao sugerido. Permanece, ainda, a necessidade de novos estudos que possibilitem a obtenção de indicadores bioquímicos mais sensíveis e específicos para o diagnóstico da deficiência de zinco na população, sobre tudo sem importantes limitações técnicas. Tal fato contribuirá para uma melhor compreensão da epidemiologia dessa carência nutricional, tornando possível identificar com maior precisão regiões com alta prevalência de deficiência de zinco ou com elevado risco de deficit nutricional. Esse entendimento é fundamental para o êxito dos programas de combate da deficiência de zinco na medida em que possibilita um planejamento mais adequado das estratégias de intervenção, com o direcionamento de ações e recursos para regiões nas quais as atividades interventivas devem ser prioritárias.

\section{COLABORADORES}

D FIGUEROA PEDRAZA participou da elaboração do projeto, revisão bibliográfica, concepção do manuscrito, análise e interpretação dos dados, redação, revisão crítica e aprovação final do artigo. MC SALES Participou da revisão bibliográfica, concepção do manuscrito, análise e interpretação dos dados, redação, revisão crítica e aprovação final do artigo.

\section{REFERÊNCIAS}

1. Gibson RS, Hess SY, Hotz C, Brown KH. Indicators of zinc status at the population level: A review of the evidence. Br J Nutr. 2008; 99(Suppl 3):14-23.

2. Mafra D, Cozzolino SMF. Importância do zinco na nutrição humana. Rev Nutr. 2004; 17(1):79-87. doi: 10.1590/S1415-5273200400100009.

3. Ferraz IS, Daneluzzi JC, Vannucchi H, Jordão Jr. AA, Ricco RG, Del Ciampo LA, et al. Prevalência da carência de ferro e sua associação com a deficiência de vitamina A em pré-escolares. J Pediatr. 2005; 81(2):169-74.

4. Silva LSV, Thiapó AP, Souza GG, Saunders C, Ramalho A. Micronutrientes na gestação e lactação. Rev Bras Saúde Mater Infant. 2007; 7(3):237-44.

5. Macêdo EMC, Amorim MAF, Silva ACS, Castro CMMB. Efeitos da deficiência de cobre, zinco e magnésio sobre o sistema imune de crianças com desnutrição grave. Rev Paul Pediatr. 2010; 28(3):329-36

6. Silva-Santana SC, Diniz AS, Lóla MMF, Oliveira RS, Silva SMM, Oliveira SF, et al. Parameters of evaluation of zinc nutritional status: Comparison between zinc hair rates and serum alkaline phosphatase in prescholars of the municipality of João Pessoa, Paraíba. Rev Bras Saúde Mater Infant. 2002; 2(3):275-82

7. César TB, Wada SR, Borges RG. Zinco plasmático e estado nutricional em idosos. Rev Nutr. 2005; 18(3): 357-65. doi: 10.1590/S1415-5273200500030 0008

8. Marinho HA, Roncada MJ. Ingestão e hábitos alimentares de pré-escolares de três capitais da Amazônia Ocidental Brasileira: um enfoque especial à ingestão de vitamina A. Acta Amaz. 2002; 33(2):263-74

9. Costa GA, Marreiro DN, Eulálio JM, Moita Neto J, Amorim AC, Nogueira AM, et al. Erythrocytary zinc and the infant growth profile in Northeast Brazil. Biol Trace Elem Res. 2008; 126 (Suppl 1):15-20.

10. Silva AP, Vitolo MR, Zara LF, Castro CF. Effects of zinc supplementation on 1-to-5-year old children. J Pediatr. 2006; 82(3):227-31.

11. International Zinc Nutrition Consultative Group. Avaliando os níveis de zinco na população através da concentração de zinco no soro. California: 
IZiNCG; 2007. Relatório Técnico nº 2 [acesso 2011 jan 11]. Disponível em: <http://izincg.org/Media/ Default/Publications/Files/Portuguese_brief2.pdf>.

12. de Benoist B, Darnton-Hill I, Davidsson L, Fontaine $\mathrm{O}$, Hotz C. Conclusions of the Joint WHO/UNICEF/ IAEA/IZiNCG: Interagency Meeting on Zinc Status Indicators. Food Nutr Bull. 2007; 28(Suppl):S480-4.

13. Ferraz IS, Daneluzzi JC, Vannucchi H, Jordão Jr. AA, Ricco RG, Del Ciampo LA, et al. Nível sérico de zinco e sua associação com deficiência de vitamina A em crianças pré-escolares. J Pediatr. 2007; 83(6):512-7.

14. Hess SY, Peerson JM, King JC, Brown KH. Use of serum zinc concentration as an indicator of population zinc status. Food Nutr Bull. 2007; 28(3 Suppl):S403-29.

15. International Zinc Nutrition Consultative Group. Assessment of the risk of zinc deficiency in populations and options for its control. Hotz $\mathrm{C}$ and Brown KH, editors. Food Nutr Bull. 2004; 25(1 Suppl 2):S91-204.

16. Brasil. Ministério da Saúde. Pesquisa Nacional de Demografia e Saúde da Mulher e da Criança. Brasília: MS; 2006.

17. Harrison WW, Yurachek JP, Benson CA. The determination of trace elements in human hair by atomic absorption spectroscopy. Clin Chim Acta. 1969; 23(1):83-91.

18. Sandstrom B. Diagnosis of zinc deficiency and excess in individuals and populations. Food Nutr Bull. 2001; 22(2):133-37.

19. Buzina R, Jusic M, Sapunar J, Milanovic N. Zinc nutrition and taste acuity in school children with impaired growth. Am J Clin Nutr. 1980; 33(11): 2262-7.

20. Thurnham DI, McCabe GP, Northrop-Clewes CA, Nestel P. Effects of subclinical infection on plasma retinol concentrations and assessment of prevalence of vitamin A deficiency: Meta-analysis. Lancet. 2003; 362(9401):2052-8.

21. Ferreira MG, Valente JG, Gonçalves-Silva RMV, Sichieri R. Acurácia da circunferência da cintura e da relação cintura/quadril como preditores de dislipidemias em estudo transversal de doadores de sangue de Cuiabá, Mato Grosso, Brasil. Cad Saúde Pública. 2006; 22(2):307-14.

22. Bergmann A, Mattos IE, Koifman RJ. Diagnóstico dolinfedema: análise dos métodos empregados na avaliação do membro superior após linfedenectomia axilar para tratamento do câncer de mama. Rev Bras Cancerol. 2004; 50(4):311-2.

23. Pitanga FJG, Lessa I. Sensibilidade e especificidade do índice de conicidade como discriminador do risco coronariano de adultos em Salvador, Brasil. Rev Bras Epidemiol. 2004; 7(3):259-69.

24. Pereira MG. Aferição dos eventos. In: Epidemiologia: teoria e prática. Rio de Janeiro: Guanabara-Koogan; 2000. p.358-76.

25. Vasconcelos FAG. Avaliação nutricional de coletividades. $3^{\mathrm{a}}$ ed. Florianópolis: UFSC; 2000.

26. Pereira TC, Hessel G. Deficiência de zinco em crianças e adolescentes com doenças hepáticas crônicas. Rev Paul Pediatr. 2009; 27(3):322-8.

27. Hambidge M. Biomarkers of trace mineral intake and status. J Nutr. 2003; 133(Suppl 3):S948-55.

28. World Health Organization. Worldwide prevalence of anaemia 1993-1995: WHO Global Database on Anaemia. Geneva: WHO; 2008.

29. Rosales FJ, Topping JD, Smith JE, Shankar AH, Ross AC. Relation of serum retinol to acute phase proteins and malarial morbidity in Papua New Guinea children. Am J Clin Nutr. 2000; 71(6):1582-8.

30. Wieringa FT, Dijkhuizen MA, West CE, NorthropClewes CA, Muhilal. Estimation of the effect of the acute phase response on indicators of micronutrients status in Indonesian infants. J Nutr. 2002; 132(10): 3061-6.

31. Villalpando S, García-Guerra A, Ramírez-Silva Cl, Mejía-Rodriguez F, Matute G, Shamah-Levy T, et al. Iron, zinc and iodide status in Mexican children under 12 years and women 12-49 years of age: A probabilistic national survey. Salud Publica Mex. 2003; 45(Suppl 4):S520-9.

Recebido em: 11/11/2012 Versão final em: 29/4/2013 Aprovado em: 24/6/2013 